Atomic Energy Levels

As Derived from the Analyses of Optical Spectra. Vol. 1: The Spectra of Hydrogen, Deuterium, Tritium, Helium, Lithium, Beryllium, Boron, Carbon, Nitrogen, Oxygen, Fluorine, Neon, Sodium, Magnesium, Aluminium, Silicon, Phosphorus, Sulfur, Chlorine, Argon, Potassium, Calcium, Scandium, Titanium and Vanadium. By Charlotte E. Moore. (United States Department of Commerce : National Bureau of Standards, Circular 467.) Pp. xliii+309. (Washington, D.C. : Government Printing Office, 1949.) 2.75 dollars.

THIS is the first volume of a series of three or four from the American National Bureau of Standards aimed at bringing up to date and replacing Bacher and Goudsmit's well-known "Atomic Energy States" (1932). Elements are being dealt with in order of their atomic number, and the first twenty. five elements covered in the present volume naturally include many of the most important.

A few pages of introduction give information on the layout and the system of spectroscopic notation, with tables of values of Landé $g$-factors, lists of predicted term-types for various iso-electronic sequences, and ionization potentials for all elements. The main tables give the designation, configuration and term energies, always expressed in $\mathrm{cma}^{-1}$ above the lowest term as zero. Data appear to be very complete for the elements covered, and include some references up to 1949 and some hitherto unpublished results.

This is a most valuable work, and the author and those associated with her are to be congratulated on getting through the laborious work of compiling this first volume. The scope of the book is, of course, limited. It only gives energy:levels, and for most work requiring actual wave-lengths or wave-numbers of lines it is still necessary to refer to original papers. Is it too much to look forward perhaps to the production of an even more useful volume on selected classified lines of the elements?

The present volume includes data for the elements in all known states of ionization. Indeed, more than three-quarters of the book is devoted to highly ionized atoms: this will appeal mainly to the specialist; but the work has thus at least the merit of completeness, and the inclusion of so much data has not apparently had any adverse effect on the price, which is remarkably reasonable for these 309 pages of tabular matter.

A. G. GAYDON

The Human Body and its Functions

An Elementary Textbook of Physiology. By Prof. C. H. Best and Prof. N. B. Taylor. Revised edition. Pp. $x i+500$. (London: Chapman and Hall, Ltd., 1949.) 18s. net.

THE names of Best and Taylor on any book on 1 physiology give assurance that it will be authoritative and well written. The present volume is a revised edition of one aimed particularly at the layman rather than the medical student. Revision has enabled the authors to include some of the more recent advances in this science. In the account of problems connected with safe blood transfusions, for example, there is a note on the $R h$ factor, now recognized as the cause of certain hitherto unexplained neo-natal deaths. The story of the vitamins is also brought up to date.

Part 1, on atoms and molecules and on protoplasm, though simply written, may make difficult reading for those with no previous scientific training; but this should not deter the reader from passing on to the rest of the book, which will be easily understandable, helped by diagrams which on the whole are good but the value of which is sometimes lessened by over-simplification.

The interest of the book is enhanced by the inclusion in some of the sections of historical details. In the excellent account of respiration, for example, history is invoked to give an explanation of the double meanings we associate to-day with the words 'inspire', 'expire' and 'inspiration'. 'The whole book is a straightforward account of the functions of the human body. It is written in simple and clear language, and will undoubtedly entertain and instruct the lay reader, for whom it is intended.

W. C. C.

\section{Catalogue of Union Periodicals}

Vol. 1 : Science and Technology Supplement. Edited by Percy Freer. Pp. 522. (Pretoria : South African Council for Scientific and Industrial Research, 1949.) n.p.

TO the "Catalogue of Union Periodicals. Volume 1 : Science and Technology", issued in 1943 for the National Research Council and National Research Board, Johannesburg (see Nature, 154, 102; 1944), a Supplement has now been issued. Again edited by P. Freer, librarian of the University of the Witwatersrand, it now includes entries relating to cement, paint, perfumery, soap and plastics, and is intended largely to replace the original 1943 volume. The new volume contains 4,758 main entries and 6,363 cross-references from 97 libraries, as against 7,175 main entries and 4,273 cross-references from 77 libraries in the original volume. New entries are distinguished by an asterisk and modifications in the arrangement, for example, one alphabetical sequence for all titles dealing with the same subject, in any one language, irrespective of country of origin, and the maintenance of a constant order for language sub divisions were made in response to suggestions received. The abbreviations of the "World List of Scientific Periodicals" are again used.

\section{Maintenance of Shade and Ornamental Trees}

By P. P. Pirone. Second edition. Pp. xvii +436. (New York and London: Oxford University Press, 1948.) 32s. $6 d$. net.

THIS work, first published seven years ago, is a

handbook for those concerned with the care of trees, and treats of many of the ills that the arboriculturist normally encounters, whether from faulty growth, pests or disease. The author is plant pathologist to the New York Botanical Garden and so writes from practical experience; the emphasis is naturally on American species and conditions, although the European grower will find much here that is useful, dealt with in simple language.

The present edition has been enlarged by a thirteenpage appendix in which brief notice is made of some of the newer insecticides such as D.D.T. and modern fungicides such as 'Fermate', as well as diseases that have assumed importance in recent years. But the most significant addition is a classified bibliography divided into sections corresponding to the various chapter subjects, which should be of considerable help to the public to whom this volume is addressed. The text is well illustrated by more than 170 figures, mostly photographic reproductions.

E. J. S. 